\title{
Adenovirus-associated acute conjunctivitis in Beijing, China, 2011-2013
}

Jie Li $i^{1,2}$, Xiaoyan Lư ${ }^{3}$, Baoming Jiang ${ }^{3}$, Yiwei Du ${ }^{1,2}$, Yang Yang ${ }^{1,2}$, Haikun Qian ${ }^{1,2}$, Baiwei Liu ${ }^{1,2}$, Changying Lin ${ }^{1,2}$, Lei Jia ${ }^{1,2}$, Lijuan Chen ${ }^{1,2^{*}}$ and Quanyi Wang ${ }^{1,2^{*}}$

\begin{abstract}
Background: Human adenovirus (HAdV)-associated acute conjunctivitis is a common infectious disease and causes significant morbidity among residents in Beijing, China. However, little is known about the epidemiology and type distribution of acute adenoviral conjunctivitis in Beijing.

Methods: Acute conjunctivitis surveillance was conducted in 18 hospitals in Beijing from July through October during 2011-2013. HAdVs were detected by PCR from eye swab and types were determined by partial hexon and fiber gene sequencing. Risk factors associated with adenoviral conjunctivitis were analyzed.

Results: Of 876 conjunctivitis cases, 349 (39.8\%) were HAdV positive. HAdV detection was most common in conjunctivitis patients aged 18-40 years; patients with contact history with a conjunctivitis case; patients with specimen collected on days 4-6 post symptom onset and patients who worked in food service as catering attendants. Fifteen types were identified among adenoviral conjunctivitis cases. Five HAdV types (HAdV-4, - 37, - 53, - 64 and - 8) accounted for $81.1 \%$ of all adenoviral conjunctivitis cases. HAdV-37, -4 and -53 were the most common types associated with adenoviral conjunctivitis in 2011, 2012 and 2013, respectively.
\end{abstract}

Conclusion: Multiple HAdV types were associated with acute conjunctivitis in Beijing. Predominant types associated with adenoviral conjunctivitis circulating in Beijing varied from year to year.

Keywords: Acute conjunctivitis, Human adenovirus, HAdV type

\section{Background}

Acute conjunctivitis is a very common medical condition [1]. Approximately $20-70 \%$ of infectious conjunctivitis is due to viruses and $65-90 \%$ of these are caused by human adenoviruses (HAdVs) [2-4]. HAdV conjunctival infections can result in diminished vision and prolonged discomfort and occasional severe sequel [4]. HAdV-associated conjunctivitis has caused significant morbidity and medical costs [4-6].

HAdVs belong to the Adenoviridae family, Mastadenovirus genus, and are further divided into 7 species (A-G) [7]. The first 51 recognized serotypes were described based on their immunologic, biologic and biochemical characteristics and subsequent types (52-68) were classified based on genomics criteria [8-14]. HAdV-3 and -7

\footnotetext{
*Correspondence: 13911209963@163.com; bjcdcxm@126.com 'Beijing Center for Disease Prevention and Control, No.16, Hepingli Middle Road, Beijing 100013, People's Republic of China

Full list of author information is available at the end of the article
}

of species B, HAdV-8, -19 , and -37 of species D, HAdV-4 of species $E$ and recently identified genotypes HAdV-53, $-54,-56$ and -64 of species D are also associated with eye infections [9, 15-21].

A previous study found that HAdV was the most prevalent pathogen associated with acute conjunctivitis in Beijing [1]. However, little is known about the epidemiology and type distribution of adenoviral conjunctivitis in Beijing. The aim of this study was to identify HAdV types associated with the acute adenoviral conjunctivitis in Beijing and describe the demographic, epidemiologic and risk factors of HAdV-associated conjunctivitis.

\section{Methods \\ Definitions}

Acute conjunctivitis, also referred as pink eye, was defined as any inflammation of the conjunctiva, which is generally characterized by a reddening of the eye with symptoms that may include pain, itching, and foreign 
body sensation accompanied by tearing or discharge [4]. Contact history was defined that a case lived, worked or studied with a conjunctivitis case or had close contact with a conjunctivitis case during the 14 days before the onset of acute conjunctivitis [7].

\section{Sample and data collection}

From July to October during 2011-2013, a total of 18 hospitals out of 113 tertiary hospitals and 155 secondary hospitals from 18 districts in Beijing were selected to participate in the acute conjunctivitis surveillance program which was designed and managed by Beijing Center for Disease Control and Prevention (CDC). The 18 hospitals are either the largest or have the most patient visits in the area. Each month, the first 5 outpatients with acute conjunctivitis diagnosed by ophthalmologists from each surveillance hospital were invited to participate in this study. The median number of clinically diagnosed acute conjunctivitis cases at enrolled hospitals in July, August, September and October was 25.0 (IQR: 18.3-65.0), 27.5 (IQR: 15.8-61.8), 25.5 (IQR: 9-49.5) and 19.5 (IQR: 1039.8), respectively. Questionnaires were designed and used by trained personnel at each site to collect demographic information, clinical information and epidemiological information. Informed consent was obtained from all participants or their guardians according to the study protocol. Eye swab samples were collected in minimum essential media (MEM) and stored at $4{ }^{\circ} \mathrm{C}$ until transfer to Beijing $\mathrm{CDC}$ for laboratory test.

\section{Sample processing}

Total nucleic acid was extracted from $200 \mu \mathrm{l}$ of sample using a MagNA Pure LC 2.0 nucleic extraction system (Roche Diagnostics Ltd. Rotkreuz Switzerland) with the MagNA Pure LC Total Nucleic Acid Isolation Kit-Large Volume following the manufacturer's instructions.

\section{HAdV detection and identification}

HAdV detection was performed by PCR assay using HotStar Taq Master Mix Kit (Qiagen GmbH, Hilden, Germany) with previously published primers [22]. HAdV positive specimens were also tested for herpes simplex virus (HSV), Chlamydiatrachomatis (Chlamydia), and the enteroviruses, Coxsackie A24 variant (CoxA24v) and enterovirus type 70 (EVA70) using previously described methods [22, 23]. For typing, HAdV hexon gene hypervariable regions 1-6 (HVRs1-6) were amplified using a nested PCR method with Premix Ex Taq ${ }^{\text {Tw }}$ DNA Polymerase Hot Start Version (Takara, Japan) with primers and cycling conditions [24]. Amplicon sequencing was performed in both directions using the amplification primers with the ABI Prism ${ }^{\circ}$ Bigdye $^{\mathrm{Tm}}$ Terminator Cycle Sequencing Ready Reaction Kit Ver. 3.1 on an ABI 3100 DNA Sequencer (ThermoFicher). Sequencher ${ }^{\text {mat }}$ 3.1.1 software
(Gene Codes, AnnArbor, MI) was used for sequence assembly and editing. For some HAdV positive specimens that could not be accurately typed by partial hexon gene sequencing, the fiber gene was sequenced using previously described primers and cycling conditions [25]. Pre-PCR, template addition and post-PCR procedures were performed in separate rooms to prevent cross contamination. Positive and negative controls were used in all PCR runs.

Predicted amino acid sequences of partial hexon gene sequences obtained in this study together with 68 prototype strains available in GenBank were aligned using ClustalW implemented in BioEdit 7.1.3. Phylogenetic trees were constructed for aligned amino acid sequences using the neighbor joining method implemented in MEGA6 software. Type determinations were based on the highest percentage identity scores and bootstrap support values (1000 bootstrap replicates) obtained by phylogenetic analysis of hexon and fiber sequence alignments comparing "unknown" and prototype strain sequences.

\section{Statistical methods}

Statistical analysis was performed using SPSS 17 software (IBM SPSS, Inc., Chicago, IL, USA). Comparisons of proportions and statistical significance were performed using the Chi-square test. A multiple logistic regression analysis was used to examine the multivariate-adjusted odds ratios (OR) for risk factors that were significant in univariate analysis. The enter method was used for screening of variables, and goodness-of-fit tests (Hosmer-Lemeshow) were performed on the logistic model. A $p$-value $<0.05$ (2-sided significance test) was considered statistically significant in the above analyses.

\section{Ethics statement}

This study was conducted in compliance with the Declaration of Helsinki, and the protocol was approved by the Human Research Ethics Committee of Beijing CDC.

\section{Results}

Demographic characteristics of conjunctivitis cases

Of 876 acute conjunctivitis cases enrolled in this study, 290 (33.1\%), 283 (32.3\%) and 303 (34.6) were obtained from 2011, 2012 and 2013, respectively. Of the study participants, 484 (55.3\%) were male. Ages ranged from 5 months to 86 years with a median age of 32 years. HAdV was detected in 119 (41.0\%), 125 (44.2\%) and 105 (34.7\%) of swab samples collected during each of the 3 years, respectively.

Type distribution of HAdV-associated acute conjunctivitis Among 349 eye swabs positive for HAdV, 342 (98.0\%) were successfully typed. Seven $(2.0 \%)$ samples were not successfully typed due to low HAdV viral load. HAdV types varied during the surveillance period of the three 
study years (Table 1). In 2011, the major types identified from conjunctival swab samples were HAdV-37 (25/119, $21.0 \%)$ and HAdV-64 (23/119, 19.3\%). In 2012, HAdV-4 $(34 / 125,27.2 \%)$ became predominant followed by HAdV-37 (24/125, 19.2\%). In 2013, HAdV-53 predominated $(22 / 105,21.0 \%)$ followed by HAdV-8 (18/105, $17.1 \%)$. In the study period, HAdV-4 (65/349, 18.6\%), HAdV-37 (61/349, 17.5\%) and HAdV-53 (59/349, 16.9\%) were the three most common types associated with acute conjunctivitis.

\section{Age and gender characteristics of patients with and without HAdV infection}

Among the 349 HAdV positive conjunctivitis patients, 203 were male and 146 were female with a male/female ratio of 1.39:1. No significant difference was observed in gender between HAdV positive cases and negative cases $(p=0.158)$ (Table 2).

The median age of HAdV positive and negative acute conjunctivitis cases were 34 years (Range: 0-78) and 30 years (Range: $0-86$ ), respectively. HAdV detection rate among conjunctivitis cases increased from 7 to 17 years of age $(39.7 \%)$, reached the peak in the age group of 18 40 years old (46.3\%), and then declined with age dramatically. Acute conjunctivitis patients aged $\geq 66$ years had the lowest HAdV detection rate (17.1\%). Multiple logistic regression analysis showed that patients aged 18-40 years were more likely to have adenoviral conjunctivitis compared with patients aged $\geq 66$ years (Table 3 ).

\section{Occupation and geographic distribution}

HAdV detection rate among acute conjunctivitis patients was significantly different among 13 occupations $(P<$ 0.001) (Table 2). Acute conjunctivitis caused by HAdV infection was lowest among physicians (15.0\%) and highest among food and beverage servers (61.54\%). Multiple logistic regression analysis showed that food and beverage servers $(p=0.005)$, followed by laborers $(p=0.01)$ and commercial service personnel $(p=0.031)$ were more likely to have adenoviral conjunctivitis compared with physician (Table 3). No significant difference of HAdV-associated conjunctivitis was found between patients living in urban or suburban settings $(P=0.859)$ or between students at school or on vacation $(p=0.980)$ (Table 2).

\section{Contact history and sampling day}

Among the 83 acute conjunctivitis patients that had contact history with a conjunctivitis case, 51 (61.4\%) had HAdV detected from eye swabs. By contrast, 36.4\% (240/ 659) of the cases without contact history had HAdV detection. The difference in HAdV detection rate among acute conjunctivitis patients with and without contact history was significant $(p<0.001)$ (Table 2). After controlling for other significant factors, persons with contact history with a conjunctivitis case were more likely to have adenoviral conjunctivitis than those without contact history (Table 3).

Of the $349 \mathrm{HAdV}$ positive eye swabs, a mixed infection was observed in 21 specimens. The most common pathogen co-detected with HAdV was Chlamydia $(n=$ $12)$ followed by HSV $(n=6)$ and CoxA24 $(n=4)$. After

Table 1 Identification of HAdV types in outpatients with acute conjunctivitis in Beijing, 2011-2013

\begin{tabular}{|c|c|c|c|c|c|}
\hline & & $2011(N=119)$ & $2012(N=125)$ & $2013(N=105)$ & Total $(N=349)$ \\
\hline Species & Type & $\mathrm{n}(\%)$ & $n(\%)$ & $n(\%)$ & $n(\%)$ \\
\hline \multirow[t]{4}{*}{ B } & HAdV-3 & $10(8.4)$ & $10((8.0)$ & $6(5.7)$ & $26(7.4)$ \\
\hline & HAdV-7 & $10((8.4)$ & $7(5.6)$ & $2(1.9)$ & $19(5.4)$ \\
\hline & HAdV-11 & $1(0.8)$ & $1(0.8)$ & $2(1.9)$ & $4(1.1)$ \\
\hline & HAdV-14 & $0(0.0)$ & $0(0.0)$ & $1(1.0)$ & $1(0.3)$ \\
\hline \multirow[t]{3}{*}{ C } & HAdV-1 & $0(0.0)$ & $2(1.6)$ & $0(0.0)$ & $2(0.6)$ \\
\hline & HAdV-2 & $0(0.0)$ & $0(0.0)$ & $2(1.9)$ & $2(0.6)$ \\
\hline & HAdV-5 & $1(0.8)$ & $0(0.0)$ & $0(0.0)$ & $1(0.3)$ \\
\hline \multirow[t]{7}{*}{ D } & HAdV-37 & $25(21.0)$ & 24(19.2) & 12(11.4) & $61(17.5)$ \\
\hline & HAdV-64 & 23(19.3) & 13(10.4) & $15(14.3)$ & 51(14.6) \\
\hline & HAdV-8 & 13(10.9) & 16(12.8) & 18(17.1) & $47(13.5)$ \\
\hline & HAdV-42 & $0(0.0)$ & $0(0.0)$ & $1(1.0)$ & $1(0.3)$ \\
\hline & HAdV-48 & $0(0.0)$ & $0(0.0)$ & $2(1.9)$ & $2(0.6)$ \\
\hline & HAdV-53 & $21(17.6)$ & 16(12.8) & $22(21.0)$ & 59(16.9) \\
\hline & HAdV-56 & $0(0.0)$ & $1(0.8)$ & $0(0.0)$ & $1(0.3)$ \\
\hline \multirow[t]{2}{*}{$E$} & HAdV-4 & 14(11.8) & $34(27.2)$ & $17(16.2)$ & $65(18.6)$ \\
\hline & Untyped & $1(0.8)$ & $1(0.8)$ & $5(4.8)$ & $7(2.0)$ \\
\hline
\end{tabular}


Table 2 Factors associated with HAdV infection in patients with acute conjunctivitis

\begin{tabular}{|c|c|c|c|}
\hline Category & $\begin{array}{l}\text { Conjunctivitis } \\
\text { cases, N }\end{array}$ & $\begin{array}{l}\text { HAdV Positive } \\
\text { n (\%) }\end{array}$ & $p$-value ${ }^{e}$ \\
\hline \multicolumn{4}{|l|}{ Gender } \\
\hline Male & 484 & $203(41.9)$ & \multirow[t]{2}{*}{0.158} \\
\hline Female & 392 & $146(37.2)$ & \\
\hline \multicolumn{4}{|l|}{ Age group (year) ${ }^{\mathrm{a}}$} \\
\hline $0-6$ & 36 & $14(38.9)$ & \multirow[t]{5}{*}{$<0.001$} \\
\hline $7-17$ & 58 & $23(39.7)$ & \\
\hline $18-40$ & 479 & $222(46.3)$ & \\
\hline $41-65$ & 233 & $78(33.5)$ & \\
\hline$\geq 66$ & 70 & $12(17.1)$ & \\
\hline \multicolumn{4}{|l|}{ Occupation } \\
\hline Children in daycare & 15 & $6(40.0)$ & \multirow[t]{13}{*}{$<0.001$} \\
\hline Children stay-at-home & 17 & $8(47.1)$ & \\
\hline Student & 89 & $32(36.0)$ & \\
\hline Teacher & 21 & $9(42.9)$ & \\
\hline Food and beverage server & 26 & $16(61.5)$ & \\
\hline Commercial service personnel & 83 & $36(43.4)$ & \\
\hline Physician & 20 & $3(15.0)$ & \\
\hline Laborer & 136 & $71(52.2)$ & \\
\hline Farmer & 85 & $24(28.2)$ & \\
\hline Government employee & 87 & $34(39.1)$ & \\
\hline Retired people & 100 & $22(22.0)$ & \\
\hline Unemployed & 84 & $33(39.3)$ & \\
\hline Other & 113 & $55(48.7)$ & \\
\hline \multicolumn{4}{|l|}{ Geographic distribution } \\
\hline Urban & 404 & $160(39.6)$ & \multirow[t]{2}{*}{0.859} \\
\hline Suburban & 472 & $189(40.0)$ & \\
\hline \multicolumn{4}{|l|}{ Student ${ }^{\mathrm{b}}$} \\
\hline Summer vacation (Jul-Aug) & 53 & $19(35.8)$ & \multirow[t]{2}{*}{0.980} \\
\hline School term (Sep-Oct) & 36 & $13(36.1)$ & \\
\hline \multicolumn{4}{|c|}{ 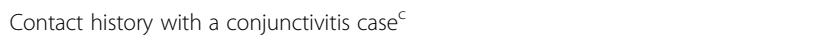 } \\
\hline Yes & 83 & $51(61.4)$ & \multirow[t]{2}{*}{$<0.001$} \\
\hline No & 659 & $240(36.4)$ & \\
\hline \multicolumn{4}{|l|}{ Sampling day after symptom onset ${ }^{d}$} \\
\hline 1 st & 156 & $46(29.5)$ & \multirow[t]{8}{*}{$<0.001$} \\
\hline 2nd & 191 & $51(26.7)$ & \\
\hline $3 r d$ & 155 & $60(38.7)$ & \\
\hline 4 th & 131 & $68(51.9)$ & \\
\hline 5th & 70 & $42(60.0)$ & \\
\hline 6th & 39 & $22(56.4)$ & \\
\hline 7th & 25 & $11(44.0)$ & \\
\hline$\geq 8$ th & 88 & $28(31.8)$ & \\
\hline
\end{tabular}

${ }^{\mathrm{a}} \mathrm{Age}$ was divided into 5 groups according to age segmentation in China ${ }^{\mathrm{b}} \mathrm{A}$ total of 89 students were included in this analysis

c134 patients were not sure if they had a contact history and were excluded from analysis. A total of 742 patients were included in this analysis

${ }^{d} 21$ mixed-infection cases were observed in this study and was excluded from analysis. A total of 855 patients were included in the analysis.Associations between risk factors and HAdV infection were done by univariate analysis ' $P$-value was conducted by Pearson's $\times 2$. The bold values means significant difference was obtained between or among compared groups
Table 3 Multiple logistic regression analysis of factors associated with HAdV infection in patients with acute conjunctivitis

\begin{tabular}{lll}
\hline Variables & $p$-value & $\mathrm{aOR}^{\mathrm{b}}(95 \% \mathrm{Cl})$ \\
\hline Gender & 0.816 & $1.037(0.762-1.413)$ \\
Age group (year) & & \\
$0-6$ & 0.832 & $0.769(0.068-8.695)$ \\
$7-17$ & 0.079 & $2.692(0.891-8.137)$ \\
$18-40$ & $\mathbf{0 . 0 2 0}$ & $\mathbf{2 . 5 9 9}(\mathbf{1 . 1 6 6 - 5 . 7 9 4 )}$ \\
$41-65$ & 0.129 & $1.802(0.842-3.857)$ \\
$\geq 66$ & Ref &
\end{tabular}

Occupations

$\begin{array}{lll}\begin{array}{l}\text { Preschool children and } \\ \text { kindergarten children }\end{array} & 0.060 & 13.533(0.895-204.588) \\ \text { Student } & 0.127 & 3.010(0.732-12.382) \\ \text { Teacher } & 0.075 & 4.147(0.867-19.842) \\ \text { Food and beverage server } & \mathbf{0 . 0 0 5} & \mathbf{8 . 7 1 3}(\mathbf{1 . 9 1 8 - 3 9 . 5 7 6 )} \\ \text { Commercial service personnel } & \mathbf{0 . 0 3 1} & \mathbf{4 . 4 3 8}(\mathbf{1 . 1 4 8 - 1 7 . 1 5 5}) \\ \text { Laborer } & \mathbf{0 . 0 1 0} & \mathbf{5 . 7 1 9}(\mathbf{1 . 5 2 - 2 1 . 5 1 8}) \\ \text { Farmer } & 0.138 & 2.845(0.715-11.327) \\ \text { Government employee } & 0.074 & 3.433(0.889-13.257) \\ \text { Retired people } & 0.235 & 2.369(0.571-9.839) \\ \text { Unemployed } & 0.064 & 3.585(0.927-13.874) \\ \text { Others } & \mathbf{0 . 0 2 3} & \mathbf{4 . 6 9 2 ~ ( 1 . 2 3 8 - 1 7 . 7 8 6 )} \\ \text { Physician } & \text { Ref } & \end{array}$

Sampling day after symptom onset

1st and 2nd Ref

$\begin{array}{lll}\text { 3rd } & \mathbf{0 . 0 4 2} & \mathbf{1 . 5 4 7}(\mathbf{1 . 0 1 6 - 2 . 3 5 5 )} \\ \text { 4th } & <\mathbf{0 . 0 0 1} & \mathbf{2 . 8 1 9}(\mathbf{1 . 8 1 0 - 4 . 3 9 1 )} \\ \text { 5th } & <\mathbf{0 . 0 0 1} & \mathbf{3 . 8 1 7}(\mathbf{2 . 1 7 1 - 6 . 7 1 3 )} \\ \text { 6th } & \mathbf{0 . 0 0 1} & \mathbf{3 . 2 6 5}(\mathbf{1 . 5 8 3 - 6 . 7 3 6 )} \\ \text { 7th } & 0.128 & 1.956(0.825-4.640) \\ \geq 8 \text { th } & 0.736 & 1.093(0.644-1.865)\end{array}$

Contact history with a conjunctivitis case

\begin{tabular}{lll}
$\begin{array}{l}\text { Not sure whether there was a } \\
\text { contact history }\end{array}$ & 0.092 & $1.423(0.944-2.145)$ \\
Yes & $\mathbf{0 . 0 0 1}$ & $2.380(1.420-3.990)$ \\
No & Ref & \\
\hline
\end{tabular}

apatients with mixed-infection were excluded

${ }^{b}$ multivariate-adjusted OR (aOR) calculated after controlling for other significant factors and gender. The bold values means significant difference was obtained when this group was compared with the reference group

removing the influence from mixed infections, we found that the HAdV detection rate in eye swabs was $29.5 \%$ on the first day of disease onset, then increased to $38.7 \%$ at day 3 , and peaked at day 5 (60.0\%) and 6 (56.4\%). A significant difference was shown in the HAdV detection rate among different sample collection days $(p<0.001)$ (Table 2). 
Multiple logistic regression analysis showed that HAdV detection rate among acute adenoviral conjunctivitis patients was significant higher from the 3th to 6th day of sampling compared with the first two days (Table 3 ).

\section{HAdV type distribution between genders and among age groups}

Analysis of the prevalence and demographic distribution of the five major HAdV types (HAdV-4, - 37, - 53, - 64 and -8 ) found significant difference in HAdV type distribution between two genders $(p=0.013)$ (Table 4). HAdV-4 (37/114, 29.8\%) and HAdV-37 (44/169, 26.0\%) were the most common type in female and male patients, respectively. $\mathrm{HAdV}-4$ positive rate among female was significantly higher than male $(p=0.003)$. No significant difference of HAdV-4 positive rate was found between children and older age groups $(p=0.320)$. No significant difference in five major HAdV types distribution was observed among different age groups $(P>0.05)$.

\section{Discussion}

This study was conducted from July through October over 3 consecutive years and 876 outpatients were enrolled in the study to determine the etiology of acute conjunctivitis in Beijing. Our results showed that HAdV was responsible for $39.8 \%$ of acute conjunctivitis cases. This result was lower than that reported in Japan during 2005-2006 (82\%) [3], Pakistan (75\%) [2] and Brazil during 2004 to 2007 (60\%) [26].

Adenoviral conjunctivitis was mainly caused by HAdV types $3,4,7,8,11,37$ and 64 which have high affinity to the conjunctival epithelium [15-19, 27-29]. In our study, a total of 15 HAdV types were identified. HAdV-4, HAdV-37 and HAdV-53 were the most common types followed by HAdV-64 and HAdV-8. This is different from previously reported studies from other countries. From 2005 to 2006 in Tokyo [3], 2000-2013 in Tunisia [30] and 2006-2010 in Turkey [31], the most common type causing adenoviral conjunctivitis was HAdV-8. Although both HAdV-4 and HAdV-8 were associated with acute conjunctivitis, HAdV-4 caused broad symptoms ranging from pharyngoconjunctival fever to adenoviral keratoconjunctivitis [32], whereas HAdV-8 was frequently associated with subepithelial corneal opacities without systemic syndrome [33]. The prevalence of membranous conjuntivitis was high (83\%) among patients infected with HAd-37 which ranked the second in Beijing [33]. HAdV-53, - 56 and - 64 are novel types which were characterized using genomics and bioinformatics $[14,34]$. In this study approximately $6.5 \%$ acute conjunctivitis was associated with HAdV-53. Similar to our findings, HAdV-53 associated epidemic keraconjunctivitis (EKC) has been identified in Japan and Germany and has recently ranked the third in Japan following HAdV-37, HAdV-54 [19]. Only one case in this study was identified as HAdV-56 which also caused keratoconjunctivitis [34], urethritis [21,35] and caused an EKC outbreak in China in 2012 [20]. HAdV-64 originating from a recombination between HAdV-19p, HAdV-37, and HAdV-22 has been closely associated with keratoconjunctivitis [17]. In this study HAdV-64 was the major type associated with acute conjunctivitis in Beijing which was accordant with a previous study [36].

HAdVs are resistant to enviromental influences and can remain infectious on surfaces for up to 4-5 weeks [4]. HAdVs can be easily transmitted through fomites contaminated with infectious body fluids. In this study, patients who had contact history with a conjunctivitis case were 2.38 times of being infected with HAdV than acute conjunctivitis patients without contact history. These results suggest that exposure to infected person can greatly increase the risk of infection. Thus, it is imperative to recommend good hand washing, avoiding sharing personal items and advocating

Table 4 Analysis of the demographic information among different HAdV types

\begin{tabular}{|c|c|c|c|c|c|c|}
\hline Characteristics $(N=283)$ & $\begin{array}{l}\text { HAdV-4 } \\
(N=64) \\
n(\%)\end{array}$ & $\begin{array}{l}\text { HAdV-37 } \\
(N=62) \\
n(\%)\end{array}$ & $\begin{array}{l}\text { HAdV-53 } \\
(N=59) \\
n(\%)\end{array}$ & $\begin{array}{l}\text { HAdV-64 } \\
(N=51) \\
n(\%)\end{array}$ & $\begin{array}{l}\text { HAdV-8 } \\
(N=47) \\
n(\%)\end{array}$ & $p$-value ${ }^{a}$ \\
\hline \multicolumn{7}{|l|}{ Gender } \\
\hline Male $(n=169)$ & $27(16.0)$ & $44(26.0)$ & $39(23.1)$ & $32(18.9)$ & $27(16.0)$ & 0.013 \\
\hline Female $(n=114)$ & $37(32.5)$ & $18(15.8)$ & $20(17.5)$ & $19(16.7)$ & $20(17.5)$ & \\
\hline \multicolumn{7}{|l|}{ Age group(year) } \\
\hline $0-6(n=11)$ & $5(45.5)$ & $0(0.0)$ & $2(18.2)$ & $2(18.2)$ & $2(18.2)$ & 0.228 \\
\hline $7-17(n=18)$ & $8(44.4)$ & $3(16.7)$ & $2(11.1)$ & $1(5.6)$ & $4(22.2)$ & 0.157 \\
\hline $18-40(n=181)$ & $38(21.0)$ & $43(23.8)$ & $37(20.4)$ & $34(18.8)$ & $29(16.0)$ & 0.796 \\
\hline $41-65(n=68)$ & $11(16.2)$ & $14(20.6)$ & $17(25.0)$ & $14(20.6)$ & $12(17.6)$ & 0.590 \\
\hline$\geq 66(n=5)$ & $2(40.0)$ & $2(40.0)$ & $1(20.0)$ & $0(0.0)$ & $0(0.0)$ & 0.951 \\
\hline
\end{tabular}

${ }^{a} P$-value was conducted by Pearson's $X^{2}$, Fisher's exact test. The bold values means statistically significance was obtained among compared groups 
isolation of the infected patients to prevent the spread of this disease [37].

We found that patients with HAdV infections in age group of 18-40 years old had 2.6 times the chance of being infected than those $\geq 66$ years old. Our observations were similar to an EKC outbreak in Germany in which all the infected patients were between 20 and 29 years old [38]. In our study, the oldest age group has the lowest HAdV detection rate probabaly because the elderly stay at home more and are less likely to contact HAdV infected patients or contaminated enviroment. Since people of 1840 years old are at high risk to be infected with acute conjunctivistis, health education on how to avoid catching this disease should be encouraged among them.

We also observed significant difference in HAdV detection among patients with conjunctivitis in 13 occupations. Among patients with acute adenoviral conjunctivitis, food and beverage workers were more likely than physicians to have HAdV as the etiology. Food and beverage workers generally have low educational level in China. According to a previous study [39], people with lower education level demonstrate lower health literacy. Since food and beverage workers are exposed to many people every day, with poor health literacy, they are more likely to be infected with HAdV. Once they get infected, they are likely to infect their colleagues and customers. To prevent and control of adenoviral conjunctivitis, food and beverage workers should be the focus of intervention. It is important for them to keep good personal hygiene habit to prevent them from being infected. Moreover, good professional responsibility should be hold. Once they get infected, they should stop working until they are fully recovered. According to the result in this study, the positive rate were the highest at the 4th, 5th and 6th day after symptom onset, we suggest that patients should be isolated in the high concentration virus excretion stage to avoid transmitting virus to other people.

A previous study reported that viral incubation time was 2-14 days and patients might remain infectious for 10-14 days after the onset of symptoms [7]. In our study, the HAdV detection rate differed significantly with the sample collection day after controlling for other significant factors. Samples collected on the ${ }^{\text {th }}$, 4 th, 5 th and 6 th day after symptom onset might be more likely to be positive than those collected on the first two days from onset. This result is consistent with the observations that secretory IgA and IgG against HAdV can be detected in serum and nasal secretions at approximately 7 days post-infection $[40,41]$. Since the virus concentration in the eye would start low in the first two days, peak on the 5th or 6th day and then decline grandually with increased antibody titer, we suggest that negtive result on an early sample should be followed by a second sample to increase the likelihood of HAdV detection. On the other hand, infected patients should be isolated especially in the high concentration virus excretion stage in order to limit infection source and prevent outbreaks in large urban areas like Beijing.

This study has several limitations. First, acute conjunctivitis surveillance was only conducted from July to October in three years, thus we were not able to perform yearround assessment of HAdV in association with acute conjunctivitis in Beijing. Second, unavailability of detailed clinical information made it impossible to establish association between HAdV types and different clinical presentations of viral conjunctivites. Third, since HAdV was detected only by PCR from eye swab and viral culture was not perfomed, we were not sure whether the virus detected on the 4th- 6th day after symptom onset remained infectious, we suggest that patients with HAdV infection during this peak shedding period were most contagious.

\section{Conclusions}

In conclusion, multiple HAdV types were associated with acute conjunctivitis among residents in Beijing. Infected person should be isolated during the period of virus excretion, especially 3-6 days after symptom onset. Good hygenic habits and disinfection of potentially contaminated environmental surfaces should be routinely practiced to reduce the spread of HAdV-associated conjunctivitis.

\section{Abbreviations \\ CDC: Center for Disease Control and Prevention; Chlamydia: Chlamydiatrachomatis; CoxA24v: Coxsackie A24 variant; EKC: epidemic keraconjunctivitis; HAdV: Human adenovirus; HSV: herpes simplex virus; IQR: interquartile range; MEM: minimum essential media; OR: odds ratios}

\begin{abstract}
Acknowledgments
We gratefully acknowledge Dr. Dean Erdman and Dr. Eileen Schneider (Centers for Disease Control and Prevention, Atlanta, GA) for contributing time, constructive comments and critical review for this manuscript. We thank those participants in this study who provided samples and clinical data and the staff of eighteen district CDCs for collecting epidemiological information and samples during the execution of this study.
\end{abstract}

\section{Funding}

This work was supported by the Capital Health Research and Development of Special (2014-1-1011).

Availability of data and materials

All original data and materials are available upon request from the corresponding author.

\section{Disclaimer}

The findings and conclusions in this report are those of the authors and do not necessarily represent the official position of the Centers for Disease Control and Prevention.

\section{Author' contributions}

$J \mathrm{~L}$ carried out the experimental design, participated in the experiment and drafted the manuscript. $X L$ and BJ participated in the experimental design, performed the data analysis and reviewed the manuscript. YD, YY and $\mathrm{HQ}$ participated in the experiment and reviewed the manuscript. $B L, C L$ and $L$ participated in the data collection, analysis and reviewed the manuscript. LC and QW contributed to the experimental design and provided a final review of this manuscript. All authors read and approved the final manuscript. 


\section{Ethics approval and consent to participate}

This study was approved by the Ethics Committee and Beijing Center for Disease Prevention and Control. Written informed consent was obtained from the participants or the guardians if participants were under 16 years of age.

\section{Consent for publication}

Not applicable.

\section{Competing interests}

The authors declare that there are no conflicts of interest.

\section{Publisher's Note}

Springer Nature remains neutral with regard to jurisdictional claims in published maps and institutional affiliations.

\section{Author details}

'Beijing Center for Disease Prevention and Control, No.16, Hepingli Middle Road, Beijing 100013, People's Republic of China. ${ }^{2}$ Research Centre for Preventive Medicine of Beijing, No.16, Hepingli Middle Road, Beijing 100013, People's Republic of China. ${ }^{3}$ Centers for Disease Control and Prevention, 1600 Clifton Road NE, Atlanta, GA 30329, USA.

\section{Received: 26 September 2017 Accepted: 28 February 2018} Published online: 20 March 2018

References

1. Li J, Yang YS, Lin CY, Li WH, Yang Y, Zhang Y, Jia L, Li XT, Chen LJ, Wang QY. Etiology of acute conjunctivitis due to Coxsackievirus A24 variant, human adenovirus, herpes simplex virus, and chlamydia in Beijing, China. Jpn J Infect Dis. 2014;67(5):349-55.

2. Woodland RM, Darougar S, Thaker U, Cornell L, Siddique M, Wania J, Shah M. Causes of conjunctivitis and keratoconjunctivitis in Karachi, Pakistan. Trans R Soc Trop Med Hyg. 1992;86(3):317-20.

3. Matsui K, Shimizu H, Yoshida A, Nagaoka E, Nishio O, Okuda K. Monitoring of adenovirus from conjunctival scrapings in Japan during 2005-2006. J Med Virol. 2008;80(6):997-1003.

4. O'Brien TP, Jeng BH, McDonald M, Raizman MB. Acute conjunctivitis: truth and misconceptions. Curr Med Res Opin. 2009;25(8):1953-61.

5. Huang SW, Tai CH, Fonville JM, Lin CH, Wang SM, Liu CC, Su IJ, Smith DJ, Wang JR. Mapping enterovirus A71 antigenic determinants from viral evolution. J Virol. 2015:89(22):11500-6.

6. Aw-Yong KL, Sam IC, Koh MT, Chan YF. Immunodominant IgM and IgG epitopes recognized by antibodies induced in enterovirus A71-associated hand, foot and mouth disease patients. PLoS One. 2016;11(11):e0165659.

7. Ghebremedhin B. Human adenovirus: viral pathogen with increasing importance. Eur J Microbiol Immunol (Bp). 2014;4(1):26-33.

8. Matsushima Y, Shimizu H, Kano A, Nakajima E, Ishimaru Y, Dey SK, Watanabe $Y$, Adachi F, Suzuki K, Mitani K, et al. Novel human adenovirus strain, Bangladesh. Emerg Infect Dis. 2012;18(5):846-8.

9. Ishiko H, Aoki K. Spread of epidemic keratoconjunctivitis due to a novel serotype of human adenovirus in Japan. J Clin Microbiol. 2009:47(8):2678-9.

10. Walsh MP, Seto J, Jones MS, Chodosh J, Xu W, Seto D. Computational analysis identifies human adenovirus type 55 as a re-emergent acute respiratory disease pathogen. J Clin Microbiol. 2010:48(3):991-3.

11. Walsh MP, Seto J, Liu EB, Dehghan S, Hudson NR, Lukashev AN, Ivanova O, Chodosh J, Dyer DW, Jones MS, et al. Computational analysis of two species C human adenoviruses provides evidence of a novel virus. J Clin Microbiol. 2011:49(10):3482-90

12. Liu EB, Ferreyra L, Fischer SL, Pavan JV, Nates SV, Hudson NR, Tirado D, Dyer DW, Chodosh J, Seto D, et al. Genetic analysis of a novel human adenovirus with a serologically unique hexon and a recombinant fiber gene. PLoS One. 2011;6(9):e24491.

13. Liu EB, Wadford DA, Seto J, Vu M, Hudson NR, Thrasher L, Torres S, Dyer DW, Chodosh J, Seto D, et al. Computational and serologic analysis of novel and known viruses in species human adenovirus $D$ in which serology and genomics do not correlate. PLoS One. 2012;7(3):e33212

14. Walsh MP Chintakuntlawar A, Robinson CM, Madisch I, Harrach B, Hudson NR Schnurr D, Heim A, Chodosh J, Seto D, et al. Evidence of molecular evolution driven by recombination events influencing tropism in a novel human adenovirus that causes epidemic Keratoconjunctivitis. PLoS One. 2009;4(6)
15. Martone WJ, Hierholzer JC, Keenlyside RA, Fraser DW, D'Angelo LJ, Winkler WG. An outbreak of adenovirus type 3 disease at a private recreation center swimming pool. Am J Epidemiol. 1980;111(2):229-37.

16. Guo DF, Shinagawa M, Aoki K, Sawada H, Itakura S, Sato G. Genome typing of adenovirus strains isolated from conjunctivitis in Japan, Australia, and the Philippines. Microbiol Immunol. 1988;32(11):1107-18.

17. Zhou X, Robinson CM, Rajaiya J, Dehghan S, Seto D, Jones MS, Dyer DW, Chodosh J. Analysis of human adenovirus type 19 associated with epidemic keratoconjunctivitis and its reclassification as adenovirus type 64. Invest Ophthalmol Vis Sci. 2012;53(6):2804-11.

18. Guyer B, O'Day DM, Hierholzer JC, Schaffner W. Epidemic keratoconjunctivitis: a community outbreak of mixed adenovirus type 8 and type 19 infection. J Infect Dis. 1975:132(2):142-50

19. Kaneko H, Suzutani T, Aoki K, Kitaichi N, Ishida S, Ishiko H, Ohashi T, Okamoto S, Nakagawa H, Hinokuma R, et al. Epidemiological and virological features of epidemic keratoconjunctivitis due to new human adenovirus type 54 in Japan. Br J Ophthalmol. 2011:95(1):32-6.

20. Huang G, Yao W, Yu W, Mao L, Sun H, Yao W, Tian J, Wang L, Bo Z, Zhu Z, et al. Outbreak of epidemic keratoconjunctivitis caused by human adenovirus type 56, China, 2012. PLoS One. 2014;9(10):e110781.

21. Idigoras P, Zapico MS, Montes M, Romano C. Simultaneous urethritis and conjunctivitis caused by adenovirus type 56. Medicina clinica. 2014;142(12):558.

22. Elnifro EM, Cooper RJ, Klapper PE, Yeo AC, Tullo AB. Multiplex polymerase chain reaction for diagnosis of viral and chlamydial keratoconjunctivitis. Invest Ophthalmol Vis Sci. 2000;41(7):1818-22.

23. Xiao XL, Wu H, Li YJ, Li HF, He YQ, Chen G, Zhang JW, Yang H, Li XF, Yang $X Q$, et al. Simultaneous detection of enterovirus 70 and coxsackievirus $A 24$ variant by multiplex real-time RT-PCR using an internal control. J Virol Methods. 2009;159(1):23-8

24. Lu X, Erdman DD. Molecular typing of human adenoviruses by PCR and sequencing of a partial region of the hexon gene. Arch Virol. 2006;151(8): 1587-602.

25. Madisch I, Harste G, Pommer H, Heim A. Phylogenetic analysis of the main neutralization and hemagglutination determinants of all human adenovirus prototypes as a basis for molecular classification and taxonomy. J Virol. 2005:79(24):15265-76.

26. Maranhão AG, Soares CC, Albuquerque MCM, Santos N. Molecular epidemiology of adenovirus conjunctivitis in Rio de Janeiro, Brazil, between 2004 and 2007. Rev Inst Med Trop Sao Paulo. 2009;51(4):227-9.

27. D'Angelo LJ, Hierholzer JC, Keenlyside RA, Anderson LJ, Martone WJ. Pharyngoconjunctival fever caused by adenovirus type 4: report of a swimming pool-related outbreak with recovery of virus from pool water. J Infect Dis. 1979:140(1):42-7.

28. Tai FH, Chu S, Chi WH, Wei HY, Hierholzer JC. Epidemic haemorrhagic conjunctivitis associated with adenovirus type 11 in Taiwan. Southeast Asian J Trop Med Public Health. 1974;5(3):342-9.

29. Keenlyside RA, Hierholzer JC, D'Angelo LJ. Keratoconjunctivitis associated with adenovirus type 37: an extended outbreak in an ophthalmologist's office. J Infect Dis. 1983;147(2):191-8.

30. Huang YP, Lin TL, Lin TH, Wu HS. Antigenic and genetic diversity of human enterovirus 71 from 2009 to 2012, Taiwan. PLoS One. 2013;8(11):e80942.

31. Huang SW, Hsu YW, Smith DJ, Kiang D, Tsai HP, Lin KH, Wang SM, Liu CC, Su IJ, Wang JR. Reemergence of enterovirus 71 in 2008 in Taiwan: dynamics of genetic and antigenic evolution from 1998 to 2008. J Clin Microbiol. 2009;47(11):3653-62.

32. Aoki K, Tagawa Y. A twenty-one year surveillance of adenoviral conjunctivitis in Sapporo, Japan. Int Ophthalmol Clin. 2002;42(1):49-54.

33. Tabbara KF, Omar N, Hammouda E, Akanuma M, Ohguchi T, Ariga T, Tagawa Y, Kitaichi N, Ishida S, Aoki K, et al. Molecular epidemiology of adenoviral keratoconjunctivitis in Saudi Arabia. Mol Vis. 2010;16:2132-6.

34. Robinson CM, Singh G, Henquell C, Walsh MP, Peigue-Lafeuille H, Seto D, Jones MS, Dyer DW, Chodosh J. Computational analysis and identification of an emergent human adenovirus pathogen implicated in a respiratory fatality. Virology. 2011;409(2):141-7

35. Hiroi S, Furubayashi K, Kawahata T, Morikawa S, Kase T. A case of urethritis caused by human adenovirus type 56. Jpn J Infect Dis. 2012;65(3):273-4

36. Robinson CM, Shariati F, Zaitshik J, Gillaspy AF, Dyer DW, Chodosh J. Human adenovirus type 19: genomic and bioinformatics analysis of a keratoconjunctivitis isolate. Virus Res. 2009;139(1):122-6.

37. Meyer-Rusenberg B, Loderstadt U, Richard G, Kaulfers PM, Gesser C. Epidemic keratoconjunctivitis: the current situation and recommendations for prevention and treatment. Dtsch Arztebl Int. 2011;108(27):475-80. 
38. Schrauder A, Altmann D, Laude G, Claus H, Wegner K, Kohler R, HabichtThomas H, Krause G. Epidemic conjunctivitis in Germany, 2004. Euro Surveill. 2006;11(7):185-7.

39. Zhang D, Wu S, Zhang Y, Yang P, Maclntyre CR, Seale H, Wang Q. Health literacy in Beijing: an assessment of adults' knowledge and skills regarding communicable diseases. BMC Public Health. 2015;15:799.

40. Walls T, Shankar AG, Shingadia D. Adenovirus: an increasingly important pathogen in paediatric bone marrow transplant patients. Lancet Infect Dis. 2003;3(2):79-86.

41. Singh-Naz N, Rodriguez W. Adenoviral infections in children. Adv Pediatr Infect Dis. 1996;11:365-88.

Submit your next manuscript to BioMed Central and we will help you at every step:

- We accept pre-submission inquiries

- Our selector tool helps you to find the most relevant journal

- We provide round the clock customer support

- Convenient online submission

- Thorough peer review

- Inclusion in PubMed and all major indexing services

- Maximum visibility for your research

Submit your manuscript at www.biomedcentral.com/submit 